\title{
THE ROLE AND ROLE OF LOGORITHMIC EXERCISES IN ELIMINATING SPEECH DEFICIENCIES
}

\author{
Lobar A. Mirakhmedova
}

Lecturer Department Of Oligophrenopedagogy Tashkent State Pedagogical University Tashkent, Uzbekistan

\section{ABSTRACT}

This article describes the role of logarithmic exercises in the development of general speech in preschool children and the role of logarithmic exercises in the elimination of speech defects.

KEYWORDS:- Logarithm, lesson, speech defects, lesson, special pedagogy.

\section{INTRODUCTION}

The birth of a healthy child depends primarily on the health of the mother. Creating a healthy environment in the family, strengthening their economic, spiritual foundations is associated with the resilience of society. The medical culture of the parents is also important in this regard. All conditions have been created in our country for the healthy birth and growth of children. Special attention is paid to children with disabilities. There are also opportunities for children in orphanages to realize and develop their talents. From kindergarten to higher education, children fully enjoy their rights and are protected from any inappropriate restrictions or abuse.

Article 31 of the Convention on the Rights of the Child states: "States Parties recognize the right of the child to rest and leisure, to participate in games and entertainment appropriate to his or her age, to participate freely in cultural life and the arts".

\section{THE MAIN RESULTS AND FINDINGS}

In this sense, the children of Uzbekistan are growing up happy, healthy and educated. It should not be overlooked that children in all countries of the world do not deserve such happiness. Many of our country's children live with passion and dreams.

Today, very important and complex work is being done in the spiritual, political and economic spheres for Uzbekistan to take a worthy place in the world. In particular, the Law of the Republic of Uzbekistan "On Education", the "National Training Program" has a socio-political significance in our country, as well as requires a new model of education. That is, through the new model of education, special attention is paid to 
CURRENT RESEARCH JOURNAL OF PEDAGOGICS 2(11): 122-125,

November 2021 DOI: https://doi.org/10.37547/pedagogics-crjp-02-11-22

ISSN 2767-3278

(C)2021 Master Journals

Crossref doi) 81 Google

Accepted 25 $5^{\text {th }}$ November, 2021 \& Published 30th November, 2021

school, preparation for life, taking a worthy place in society.

In carrying out these tasks, it is important to overcome the speech impediment of children of preschool age with incomplete speech with the help of logarithmics. Because preschool education also aims to fully shape the child's personality in a healthy and mature way, ready for school.

For the correctional development of speech of preschool children with incomplete speech using logarithmics, it is important to combine speech, mental, moral, labor and physical activity.

Therefore, the comprehensive development of the personality of a child of preschool age consists of a set of verbal, physical, mental, labor and aesthetic education.

In this regard, the advanced ideas of Central Asian thinkers on education are very valuable to us.

Abu Nasr al-Farabi (873-950), Abu Ali Ibn Sina (980-1037), Abu Rayhan Beruni, Ulugbek, Kaykovus, Al-Khwarizmi, Al-Farghani and others said, expressed the views that.

The great scholars Al-Bukhari, Abu Abdullah, AlKhwarizmi, Abu Rayhan Beruni, Abu Nasr alFarabi, Ibn Sina, Zamakhshari have written works on language, speech, dictionary, grammar and logic.

Abu Ali Ibn Sina and Abu Nasr al-Farabi say that the future of children should be taken care of before he is born, and that from an early age he should be taught such qualities as honesty, responsibility, and kindness.

The issue of cultivating meaningful, beautiful, effective speech has long fascinated people. In addition to natural-scientific, philosophical, socio-political, and ethical issues, encyclopedic scholars have created dozens of works on the positive effects of musical rhythmics on the human psyche in music theory.

Abu Nasr al-Farabi, an encyclopedic scholar of the early Eastern Renaissance, described his direct opposition to music theory from such works as The Book of Rhetoric and The Book of Rhythm Series. He gave examples in his works about the health-improving aspects of music, which educates human morals, and about the wonderful properties of melodies and movements.

Logarithmic exercises are important in overcoming speech impediments in preschool children with incomplete speech development. In the lessons of musical rhythmics, logarithmics plays a specific active corrective - speech therapy therapeutic function. In it, the combination of words and music with actions serves to correct, heal and develop speech defects.

The unique national musical heritage of the Uzbek people, its surroundings, life, the nature of the seasons, the beauty of nature, human labor, is reflected in the world of the first perception of the young.

Therefore, special logarithmic upbringing of children with speech immaturity is a requirement of today.

At a time of radical changes in the current education system, pedagogues, speech therapists, especially leading specialists of the Republic, are responsible for investigating the causes of incomplete speech in preschool children and solving them as early as possible. A deeper study of it, both theoretically and practically, is a requirement of today.

Russian scientists have studied the science of speech therapy in depth. Incomplete development of speech in the field of defectology is the psychological and pedagogical side of R.E. Levina (1951 - 1961), the psychological and linguistic side of VK Orfinskaya (1959-1963), EF Sobotovich (1984), VA Kovshikov. (1985), 
CURRENT RESEARCH JOURNAL OF PEDAGOGICS 2(11): 122-125,

November 2021 DOI: https://doi.org/10.37547/pedagogics-crjp-02-11-22

ISSN 2767-3278

(C)2021 Master Journals

Crossref do: 81 Google

Accepted 25th November, 2021 \& Published 30 ${ }^{\text {th }}$ November, 2021

EMMastyukova (1973) created the scientific and practical basis.

In Uzbekistan, during the years of independence, positive changes have begun to appear in the development of speech therapy. What is gratifying now is that in Central Asia, we have made some progress. It should be noted that L.R.Muminova, M.Yu.Ayupova, H.M.Shomahmudova, H.Pulatova, D.Nurkeldieva, P.M.Pulatova, M.P.Khamidova, L.Sh. The services of Nurmukhamedova and others are great.

One of the various aspects of the problem of incomplete development of speech was observed in the research of AK Markova, ON Usanova.

The correctness of speech is its main moral quality. Properly structured speech ensures that the parties - the speaker and the listener, the writer and the children - understand each other quickly and easily, and if the speech is not correct, it will be neither purposeful nor logically consistent. "When we say correct speech," VG Kostomarov writes, "it is necessary to understand the strict and precise adherence to the norms of language adopted at a given time, to master its pronunciation, spelling, vocabulary and grammatical norms." So, the correctness of speech is, first of all, its conformity to the norms of literary language.

The ability and use of language by members of the community in the process of mutual exchange of ideas has its own set of laws. One common denominator is that everyone has the ability to use their mother tongue or any language they speak as needed. This ability is based on the intellectual traits that have been passed down from generation to generation in human observation and the traditions of thought that have been repeated in each individual for generations.

In any case, the culture of speech is, first of all, the formation of speech skills, speech skills. This ability is a verbal-practical process, an ability, a skill that is achieved through special work and exercise, through exercise and practice.

This is what B.A. Mahmutova describes. "Speech culture is a matter of being able to express an opinion correctly, clearly and expressively. The ability to expressively express the knowledge of the rules of pronunciation (orthoepy) and the features of the phonetics of the Uzbek language plays a special role in the acquisition of oral skills. Speech observation, pronunciation exercises are important.

Another important feature of logarithmics that meets today's demand is that it performs the function of healing from speech-impaired children of preschool age. Another task of logoritmikaiing, including the harmonious development of the child's body shape and function, increase work capacity, increase resistance to various challenges, ensure longevity, is to improve the necessary skills and abilities, to eliminate speech defects, to make children physically healthy, energetic and beautiful. is a diligent upbringing.

Logarithmics is of great theoretical and practical importance. It is determined by the social nature of the nugget, the child's speech, the gafakkuri of his actions, and the close connection of his emotional, mental activity today.

The function of speech is one of the most important spiritual functions of man.

In the process of speech development, higher forms of cognitive activity, comprehensible thinking skills are formed. The meaning of the word is self-generalizing, and in this respect it reflects not only the unity of speech, but also the unity of thought. They are not exactly the same and to some extent do not depend on each other. but in the process of mental development of a child of preschool age a complex, qualitatively new unit of speech thinking, speech thinking 
CURRENT RESEARCH JOURNAL OF PEDAGOGICS 2(11): 122-125,

November 2021 DOI: https://doi.org/10.37547/pedagogics-crjp-02-11-22

ISSN 2767-3278

(C)2021 Master Journals

Crossref do) 81 Google

Accepted 25th November, 2021 \& Published 30 ${ }^{\text {th }}$ November, 2021

activity emerges.

The acquisition of verbal communication skills lays the groundwork for specific human social connections. As a result, the preschooler's perception of the environment is formed and clarified. The forms of its reflection improve.

Mastering a preschooler's speech helps him or her understand, plan, and regulate his or her behavior.

Speech communication creates important conditions for the development of various forms of activity and participation in team work.

Speech disorders, unrestricted speech problems have a negative impact on the formation of the child's personality, cause non-existent mental disorders, specific features of the emotionalvolitional sphere, pave the way for the development of negative qualities of his character (shyness, indecision, humanity, negativity, imperfection). possible.

All this has a negative impact on the preparation of preschool children for school, literacy, mastery in general.

\section{Conclusion}

In conclusion, the importance of logarithmic training, speech therapy in the development of speech in children of preschool age with incomplete speech development is to develop the child's speech, to eliminate speech defects, and at the same time to ensure the full development of the child.

\section{REFERENCES}

1. Levina R.E. Basic theory and practice of speech therapy. 2013 Publishing: Alyans

2. Muminova L.R. Speech therapy Tashkent -
"O‘qituvchi" 1993.

3. Ayupova M.Yu. Speech Therapy Publishing House of the National Society of Philosophers of Uzbekistan. Tashkent, 2007

4. Pulatova X.M. Speech therapy rhythm Tashkent-2015 y.

5. Djuraeva, N. D. (2019). Study of issues of attitude to the place and role of women of Uzbekistan in society in the XX century. Academia Open, 1(1).

6. Djuraeva, N. D. (2020). THE PLACE AND ROLE OF WOMEN IN SOCIETY IN THE PRE-ISLAMIC PERIOD. INTERNATIONAL SCIENTIFIC AND TECHNICAL JOURNAL "INNOVATION TECHNICAL AND TECHNOLOGY”, 1(2), 62-68.

7. Dalibaevna, N. D. (2021). The Social Activity of Women Is One of the Important Factors in the Development of the Country. Eurasian Journal of Social Sciences, Philosophy and Culture.

8. Sayfullaev, N. (2021). The Name of Our Country Will Be Praised By The Followers of Kamoliddin Bekhzod. The American Journal of Social Science and Education Innovations, 3(04), 402-408.

9. Karimov, N. R. (2020). A True Successor of Great Central Asian Scholars. Journal «Bulletin Social-Economic and Humanitarian Research,(7), 62-69.

10. Verdolini, K., \& Ramig, L. O. (2001). Occupational risks for voice problems. Logopedics Phoniatrics Vocology, 26(1), 37-46.

11. Cosman, B., \& Falk, A. S. (1980). Delayed hard palate repair and speech deficiencies: a cautionary report. The Cleft palate journal, 17(1), 27-33. 